\title{
Exploring Territorial Imbalances: A Systematic Literature Review of Meanings and Terms
}

\author{
Stefania Oppido ${ }^{(\triangle)}(\mathbb{D})$, Stefania Ragozino (D), \\ and Gabriella Esposito De Vita (D) \\ Research Institute for Innovation and Services for Development, \\ National Research Council of Italy, 80134 Naples, Italy \\ s.oppido@iriss.cnr.it
}

\begin{abstract}
Within the framework of the EU Strategies of Territorial Cohesion, a relevant role is played by policy design focused on a more balanced and equal development of regions pursued by regenerating and improving endogenous resources. A place-sensitive instead of place-neutral approach can be useful to overcome weaknesses, innovation gaps and social-economic issues related to asymmetric and unequal development between and within regions. This paper deals with the complexity of territorial imbalances and spatial inequalities by focusing on lacking, declining and marginal areas. By developing a Systematic Literature Review, a first mapping of terms, practices and issues related to those areas has been developed in order to investigate scenarios in different geopolitical contexts and at various spatial scales. The Systematic Literature Review approach has permitted the systematization of a multitude of terms referring to gaps between core areas and areas suffering from territorial imbalances, as well as the exploration of disciplinary sectors, geographical contexts, document typologies, frequency of terms, and to develop a preliminary geo-localization of practices. The findings of this first step are relevant to providing a systematic knowledge base within a complex field in which a clarification of meanings, scales and processes is needed.
\end{abstract}

Keywords: Cohesion policy $\cdot$ Place-based approach $\cdot$ Inner peripheries

\section{Introduction}

The European Cohesion Policy 2014-2020 has been strongly dedicated at improving Knowledge and Innovation as drivers to overcome the development issues affecting regions and cities and to build an operative framework for smart, sustainable and inclusive growth [1]. Regions have been invited at playing an incisive role in designing tailored policies toward the current challenges of our society, by valorising endogenous resources. At regional level, following a place-based approach, a policy design focused on a more balanced and equal development has been strongly encouraged via the Smart Specialisation Strategies (S3) aimed at improving competitiveness in the globalised market starting from local resources and competencies [2]. Nevertheless, at the end of the last programming period, there are still regions with unsolved structural 
weaknesses, highlighting an innovation gap, and the spread of shrinking and marginalisation processes in urban peripheries, small cities, and inner areas. Therefore, across many countries, in last decades, models of economic growth have generated an increasing polarisation between attractive core areas and areas suffering decline and deprivation processes, making them lagging and peripheral [3-6]. Starting from this evidence, the new steps of EU cohesion policies (2021-2027) are geared to a more tailored approach to regional development under the flagship of solidarity and spatial equality, targeting the complexity of territorial imbalances through regeneration processes. During the Italian Presidency of the EU Council (July-December 2014), the debate about this issue has been encouraged [7], according to the Italian National Strategy for Inner Areas SNAI (2014) which is part of the European Cohesion Policy and promotes a place-based approach [8].

Within this scientific debate and political agenda, the ongoing research project "Territorial Imbalances and Marginalisation Processes. The Landscape as a Driver for the Regeneration of Small Villages and Inner Areas" at CNR IRISS deals with placebased regeneration strategies in areas that suffer inequality development processes, with a specific in-depth focus on Italian context, starting from the framework of the SNAI. By contributing to the working group "Aree interne e dintorni" (Inner areas and surroundings) within the Italian Planning Society, the researchers focus on the Italian scenario by observing inequalities not only in the areas defined as "inner" by the SNAI, as well as launching a critical debate on policies and practices. By analysing the Italian scenario, researchers registered a relevance of the Italian role within the European debate, but also a very specific perspective, which does not permit generalization in an international framework. For these reasons, research activities are focusing on:

- Deepening the Italian scenario implementing a first empirical case study (Irpinia area in Campania Region) with an Action Research protocol finalised to build an action arena - coherent with the place-based approach $[9,10]$.

- Understanding the phenomenon of areas suffering territorial imbalances in an international framework. Geographic and economic remoteness, negative economic and demographic trend as well as exclusion from economic, institutional and cultural networks and from decision-making [3, 6, 11-14] are recurring conditions that affect local development, triggering the risk of progressive territorial de-generation processes [15].

This paper regards the process to decode this complex issue, considered relevant within the political and scientific debate. A preliminary screening of literature highlighted the multidisciplinary character of the debate including regional and urban studies, economics, social science and environmental studies. The main evidence of this activity has been the identification of a multitude of terms referring to areas affected by conditions of decline or inequalities, and has stimulated the following research questions: How do you intend these areas in different geo-political and disciplinary contexts? Are the different terms synonymous or do they refer to different situations?

Starting from these questions, research activities have been aimed at decoding different meanings and collecting practices and issues in an international scenario by developing a Systematic Literature Review (SLR). Having built a database and tested 
the SLR method on the first 100 eligible documents, researchers widened the application of the method to the entire database to implement a quantitative analysis.

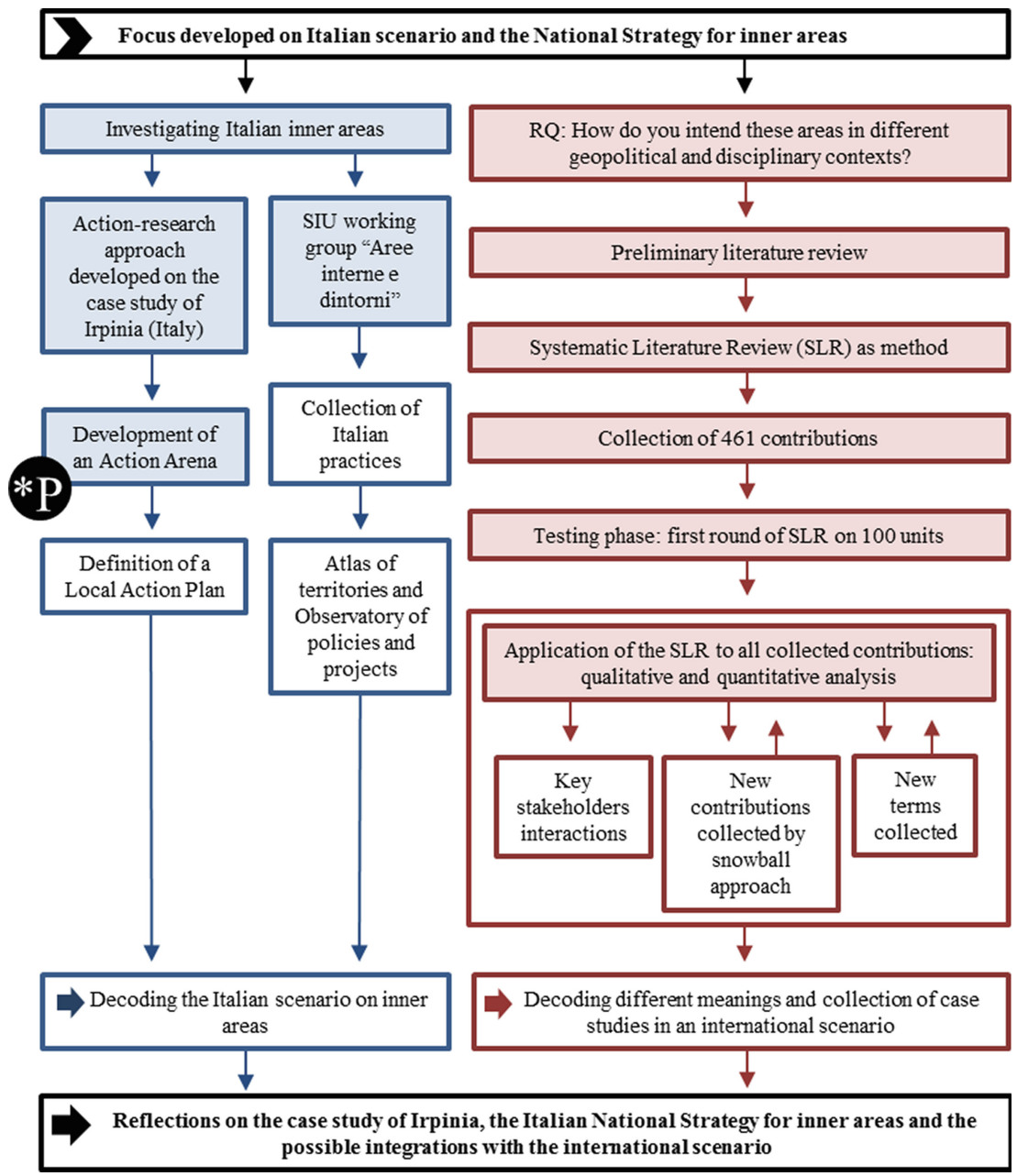

Fig. 1. Phases of the methodology (Author's elaboration)

The Fig. 1 shows phases of the methodology to achieve the comparison between the Italian scenario (left column of the Figure) and the international scenario (right column) in order to generate reflections and possible integration. The boxes with the coloured background represent stages of research already developed or in progress and the symbol "P" refers to a step of scientific dissemination. Following this introduction, the paper describes the SLR, illustrates the data collection, analyses the first findings and discusses the research follow-up. 


\section{SLR to Investigate the Multitude of Terms}

The Systematic Literature Review (SLR) is a theoretical framework used to map existing studies related to a specific topic. This method represents the way to be exhaustive within the huge amount of documents collected in scientific databases [16]. Specifically, a codified systematic review consists of «[...] a clearly formulated question that uses systematic and explicit methods to identify, select, and critically appraise relevant research, and to collect and analyse data from the studies that are included in the review. Statistical methods (meta-analysis) may or may not be used to analyse and summarise the results of the included studies» [17]. In this research, the SLR has been used to explore, deepen and systematize the multitude of terms referred to areas suffering for territorial imbalances.

After a testing phase of the proposed methodology presented at the 2019 AESOP Congress [18], this paper deals with the application of the SLR to all collected documents by analysing them in a quantitative manner and preparing the next phase of qualitative analysis. According to Bramer et al. 2017 [19], a combination of databases is needed to conduct efficient SLR. Nevertheless, the specificity of this research, which observes a multitude of terms and not only one main topic, led to use Web of Science (WoS) as selected database, in order to develop, modify and save structured advanced search through field tags, Boolean operators, parentheses, as well as to frame query within the WoS Categories, filtering subject categories of every source covered by WOS Core Collection. The data collection has been recorded in the database in which every set of data emerged from WoS were migrated to Mendeley (for avoiding redundancies) and then to Excel. The database was structured including each information available in Mendeley [18] and additional five columns to filter disciplinary sectors, geographical contexts, document typologies, emerged items, and location of practices. The emerged items were analysed by forming the highest level of alternatives made by combining all adjectives (inland, inner, interior, internal, marginal*, non-core, peripher*) with multiple substantives (area*, context*, territory*, and landscape*). Researchers obtained seven queries like this one:

ts $=[$ (“inland area*") OR ("inland context*") OR ("inland territor*") OR ("inland landscape*”)]

Table 1. Filter used to launch the advanced search in WOS

\begin{tabular}{l|l}
\hline Filter & Characteristic \\
\hline Language & English \\
\hline Time span & $1965-2018$ \\
\hline $\begin{array}{l}\text { Typology of } \\
\text { document }\end{array}$ & Scientific articles, books/chapters and conference proceedings \\
\hline Database & Web of Science Core Collection (Citation Indexes) \\
\hline Subject category & $\begin{array}{l}\text { Agricultural Economics \& Policy, Regional \& Urban Planning, Social } \\
\text { Issues, Cultural Studies, Demography, Urban Studies, Development } \\
\text { Studies, and Economics }\end{array}$ \\
\hline
\end{tabular}


Each query was investigated by structuring the advanced search with the filters presented in the Table 1. Once the database was formed, an analysis of the documents one by one was carried out, then additional information was archived, such as frequency analysis, focus on the most used items and focus on practices location.

\section{First Findings}

The flow chart in Fig. 2 describes the adopted SLR approach coherently with the PRISMA Statement [20], which includes 4 phases: identification, screening, eligibility, and inclusion; the infographic presents percentage emerged.

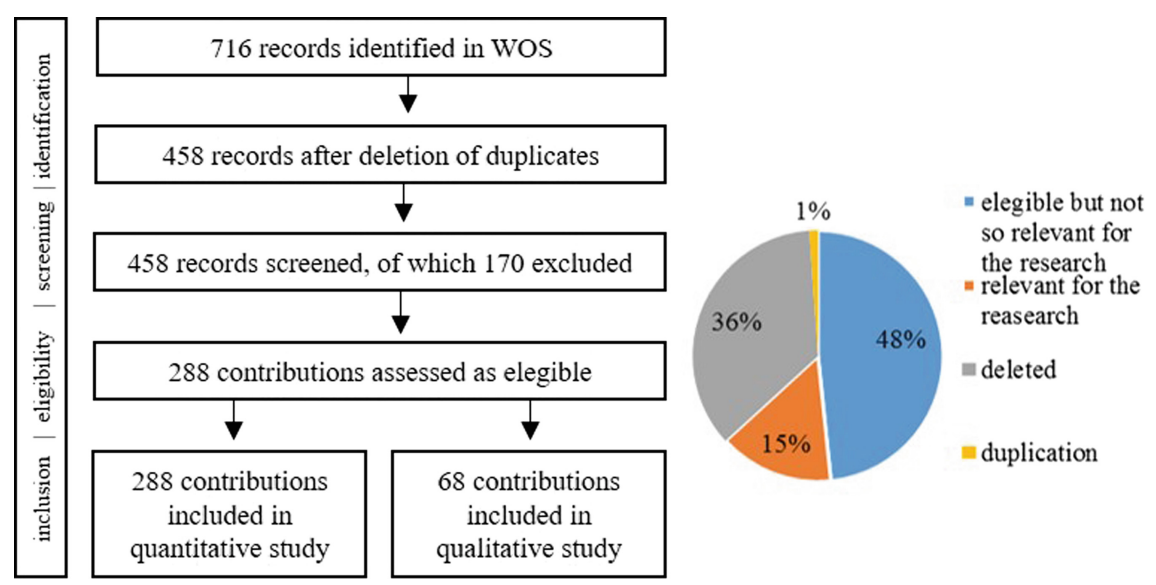

Fig. 2. Flow chart for a SLR (Author's elaboration starting from Moher et al., 2015)

Following frequency analysis, a focus on the most used items and on practices location was developed on the eligible 288 documents. Following a scientometric approach, the relevance of the topic overtime has been appreciated through the distribution on the timeline (Fig. 3). During the investigated time span (1965-2018), the first documents were published on 1978, following the institution of the European Regional Development Fund (ERDF), set up in 1975 to correct regional imbalances due to predominance of agriculture, industrial change and structural unemployment.

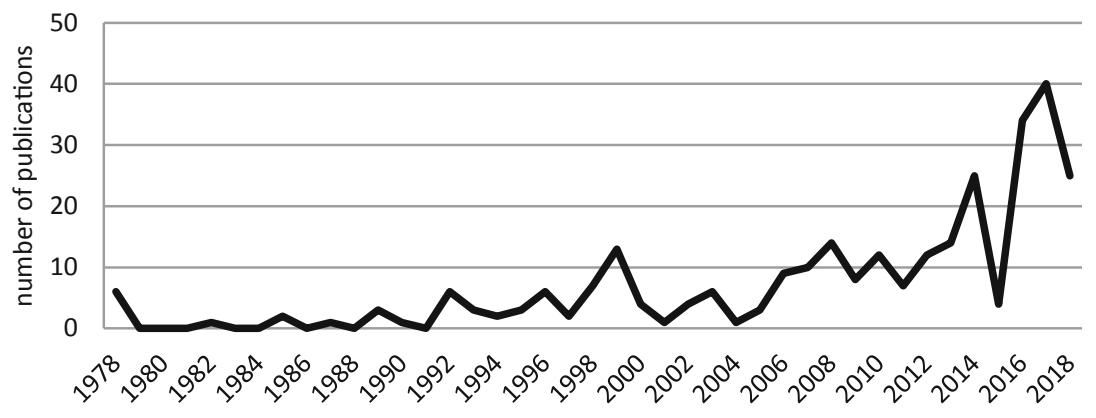

Fig. 3. Distribution of publication overtime (Author's elaboration) 
The main part of the documents is concentrated in the period after the 1999 and presents four main steps in time: 1999, 2008, 2014 and 2017. The first one could be referred to the resulting interest in the 1993's Maastricht Treaty, which introduced the Cohesion Fund, the Committee of the Regions, and the principle of subsidiarity; and to the doubled resources for the structural and cohesion funds for the period 199499 (ECU 168 billion). The second step could be linked to the third block of cohesion policies (2007-2013) in which the budget was $€ 347$ billion focused on research, innovation, environmental infrastructure and measures to combat climate change. On 2014 the Italian Presidency of the EU Council promoted a vibrant debate about inner areas, the Italian SNAI was launched, and started the fourth block of the cohesion policies (2014-2020). During the year 2017, there was a massive scientific production emblematic of the success of the topic within the political and scientific debate.

Secondly, the scientometric approach recommends observing the document typology. In the case of this search, journal articles are 214 units, conference proceedings 59 and book/book Sect. 15. The low number of book/book section, which is considered the public approved science, tells us that these topics are still in process and that there is an explorative approach in which initiatives and practices are presented.

First findings referred to the additional filters are presented below. With regard to the disciplinary sectors (Fig. 4) that were observed, Urban and Regional Studies is the most populated together with the Economics and this testify that the issue of territorial imbalances is mainly a challenge between these two areas.

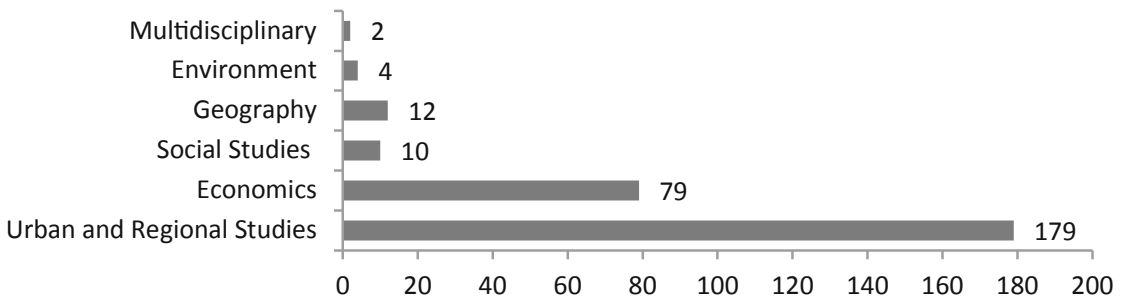

Fig. 4 Disciplinary sectors (Author's elaboration)

Analysis of the geographical contexts shows the dominance of Europe and Asia (Fig. 5). The fact that Europe is more present than the bigger continents suggests its greater sensitivity to this issue, a different commitment in terms of policies and a historicity of phenomena related to territorial imbalances. Asia is the second with half the points compared to Europe and this could be representative of the complex asset of Chinese territories that suffered for recent and strong development policies.

The screenshot related to the document typologies, in which the practices are more than the $70 \%$ of the products, is quite predictable due the objects of the analysis (Fig. 6) and help understanding location and contents of practices at international level. 


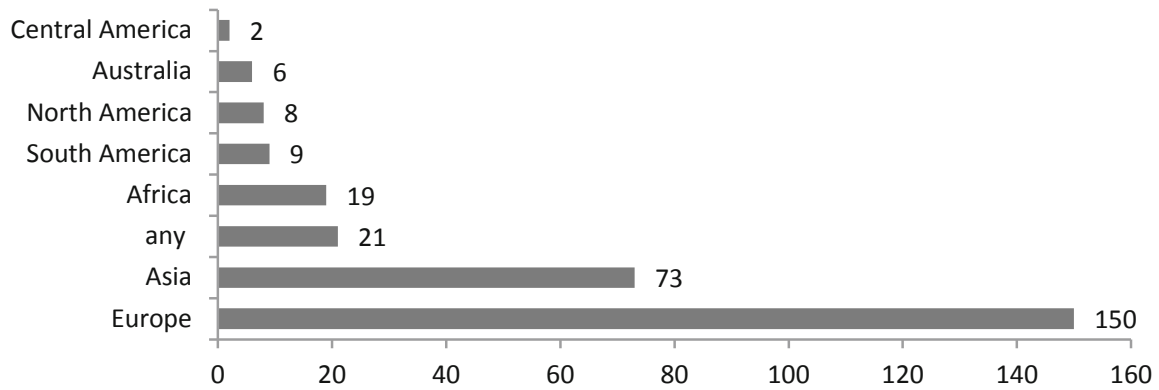

Fig. 5. Geographical contexts (Author's elaboration)

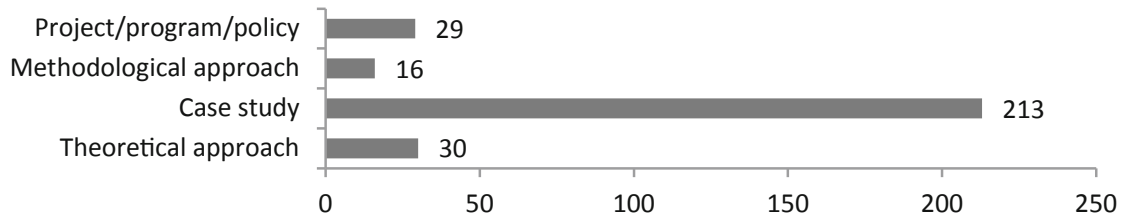

Fig. 6. Document typologies (Author's elaboration)

Four items on eighteen emerged as dominant and are all terms consisting of the substantive "area": peripher* area* (121), marginal* area* (59), inland area* (46) and inner area* $(22)$. The term peripher* area* is the most present in the database representing twice as much as the second term for presence. Authors developed two analyses on this set of data. The first one is referred to the use of these terms overtime (Fig. 7) and shows the constant increasing of the term peripher* area* with one decreasing period (2001-2005). It is noticeable the increasing in the use of inland area* since 2011, the massive presence of marginal* area* during the two periods 2006-2010 and 2011-2015, the consolidated use of the term inner area* in the period 2016-2018.

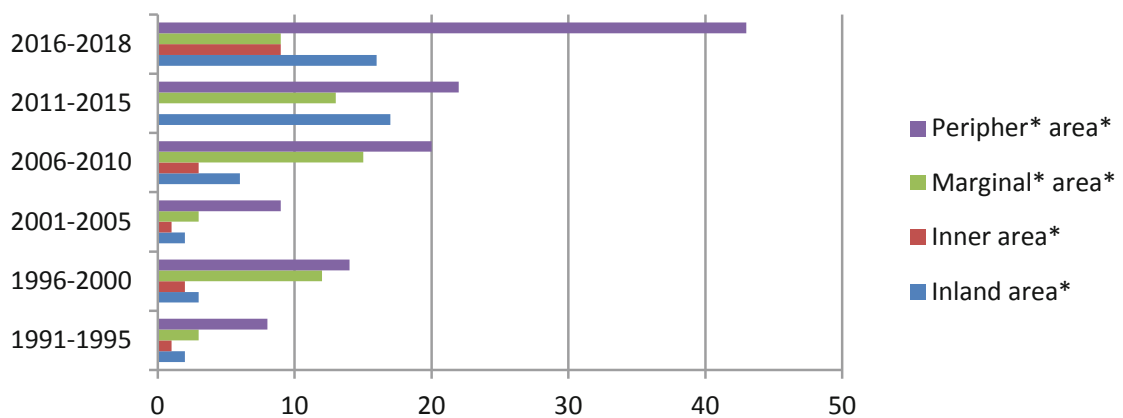

Fig. 7. Presence of emerged items overtime (Author's elaboration) 
The second one is referred to the use of these terms worldwide (Fig. 8) and shows that in Asia the terms inland area* and peripher* area* are more frequent, in Africa marginal* area* and in Europe peripher* area. For the Europe case, the influence to use this term could be related to the promotion of ESPON's GEOSPECS program where the topics of this research are discussed under the "Inner Peripheries" umbrella concept. The term inland area* is more present in Asia, while inner area*, marginal* area* and peripheral* area* in Europe.

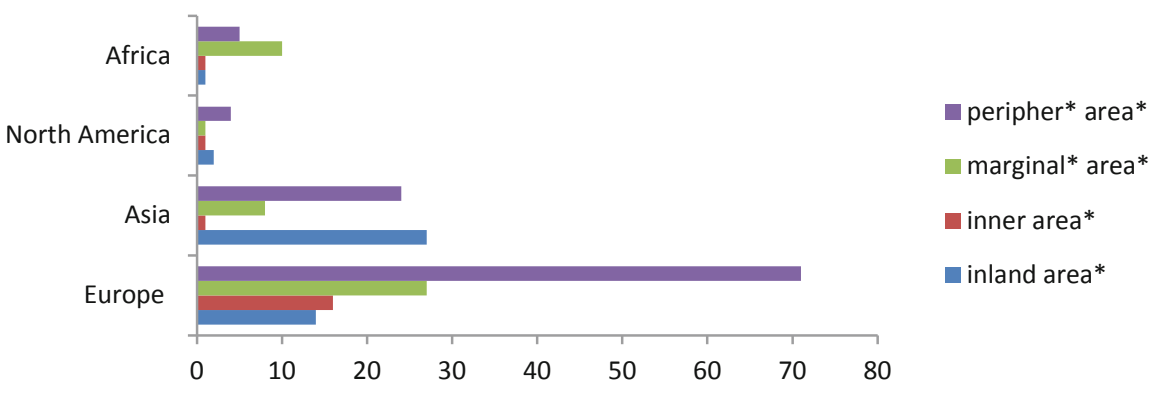

Fig. 8. Presence of emerged items around world (Author's elaboration)

Considering the massive number of practices, a geo-localization has been developed in order to observe the distribution and the trend of the phenomenon of territorial inequalities. The first four countries most populated in terms of practices are China (43), Italy (21), United Kingdom (14) and Spain (10) (Fig. 9).
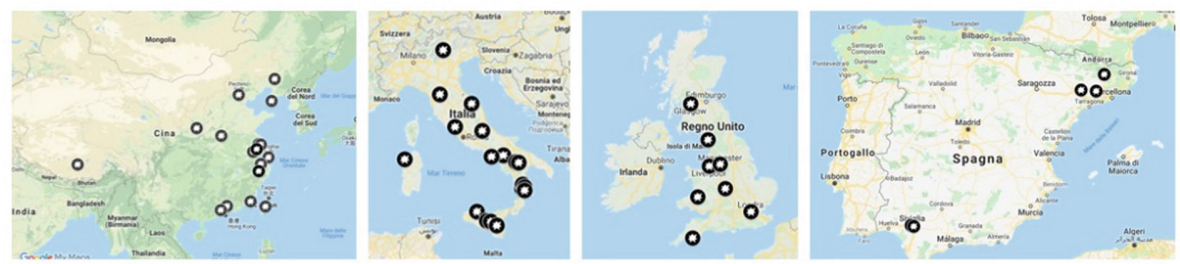

Fig. 9. Mapped practices in China, Italy, UK and Spain (Author's elaboration)

In China, it is possible to observe that the whole concentration of published practices regards the eastern side of the country of which the cost is rich. A different situation is showed in Italy where the SNAI recognises the phenomenon of territorial imbalances in those territories far from the main core areas and then localised along the central Apennine. In UK, the location of practices is a mix of coastal and internal areas. In Spain, there are only two separate areas in which the practices are located, Catalonia 
and Seville. Resulting from the analysis, new terms have been detected: northern peripheries, resource peripheries, peripheral rural areas, marginalised community, peripheral centrality, fringe areas, less developed areas, inland locations, inland people, borderland region, peripheral region, peripheral cities, northern peripheries and noncore regions. In the next steps, these terms will be implemented in the database in order to cover a wider range of disciplinary sectors and geographical contexts.

\section{Preliminary Discussion}

As highlighted in the Barca's Report [21], a shift toward a place-based approach, if well implemented, could be useful to improve the capacity of a region to exploit its territorial potential and to achieve equity principles among their citizens [22]. According to this, a place-based approach - by combining peculiarities of territorial capital and social innovation opportunities - could represent the next step for rethinking S3 as cohesion and balancing tool to overcome development gaps among catalyst and lacking areas [23].

In the ongoing research, the selection of SLR method has permitted to systematize the multitude of terms referred to gaps between core areas and areas suffering for territorial imbalances and to explore disciplinary sectors, geographical contexts, document typologies, frequency of terms overtime and around world, and a preliminary geo-localization of practices. With regard to the follow-up phase, the research agenda includes the implementations of emerged terms in the SLR database, the collection and analysis of new documents derived from the snowball approach and from the engagement of stakeholders, and finally the qualitative analysis.

Relevant documents have highlighted that the scientific debate about areas suffering for territorial imbalances as result of complex processes producing social-spatial disparities «[...] reflected in the growing use of terms such as "peripheralization" and "marginalization"» [6: 368]. A sector of literature links the peripheralisation processes to the lack of innovation in terms of economic polarization theory, to the production of socio-spatial disadvantages in terms of social inequalities theory, to the conditions of dependency and exclusion in terms of political theories [6].

The research agenda includes a focus on peripheralisation and marginalisation processes that enriched the decoding phase with methodological and theoretical approaches as well as projects, programs and policies to be added to practices already collected by previous research activities. Additional reflections could be dedicated to identify where are located research centres and networks involved in these issues, to photograph in time practices, projects, programs and policies and highlight possible correlation between them.

Acknowledgment. This research is part of the TREnD project (Transition with Resilience for Evolutionary Development), which has received funding from the European Union's Horizon 2020 research and innovation program under the Marie Skłodowska-Curie grant agreement No. 823952. 


\section{References}

1. European Commission: Europe 2020: Europe's Growth Strategy. European Commission Directorate-General for Communication Publications, Brussels (2012)

2. Foray, D.: Smart Specialisation: Opportunities and Challenges for Regional Innovation Policy. Routledge, London \& New York (2014)

3. Bertolini, P., Pagliacci, F.: Quality of life and territorial imbalances. a focus on italian inner and rural areas. Bio-Based Appl. Econ. 6(2), 183-208 (2017)

4. Copus, A., Mantino, F., Noguera, J.: Inner Peripheries: an oxymoron or a real challenge for territorial cohesion? Ital. J. Plann. Pract. 7(1), 24-49 (2017)

5. Copus, A., Melo, P.C., Kaup, S., Tagai, G., Artelaris, P.: Regional poverty mapping in Europe-Challenges, advances, benefits and limitations. Local Econ. 30(7), 742-764 (2015)

6. Kühn, M.: Peripheralization: theoretical concepts explaining socio-spatial inequalities. Eur. Plann. Stud. 23(2), 367-378 (2015)

7. Servillo, L., Russo, A.P., Barbera, F., Carrosio, G.: Inner peripheries: towards an EU placebased agenda on territorial peripherality. Ital. J. Plann. Pract. 6(1), 42-75 (2016)

8. Barca, F., Casavola, P., Lucatelli, S.: A strategy for inner areas in Italy: definition, objectives, tools and governance. Mater. UVAL 31 (2014)

9. Oppido, S., Ragozino, S., Micheletti, S., Esposito De Vita, G.: Sharing responsibilities to regenerate publicness and cultural values of marginalised landscapes: case of Alta Irpinia, Italy. Urbani Izziv 29(Special Issue Public Space for Local Life), 125-142 (2018)

10. Oppido, S., Ragozino, S., Icolari, D., Corvigno, V., Esposito De Vita, G.: Patrimonializzazione del paesaggio irpino: verso comunità di paesaggio sperimentando la ricerca-azione. In: XXII Conferenza Nazionale SIU Società Italiana degli Urbanisti - L'Urbanistica Italiana di fronte all'agenda 2030 per lo Sviluppo Sostenibile (2020)

11. ESPON: Processes, Features and Cycles of Inner Peripheries in Europe (PROFECY). The need for integrating inner peripheries (2017)

12. Pezzi, M.G., Urso, G.: Peripheral areas: conceptualizations and policies. Introduction and editorial note. Ital. J. Plann. Pract. 6(1), 1-19 (2016)

13. Herrschel, T.: Regional development, peripheralisation and marginalization and the role of governance. In: Herrschel, T., Tallberg, P. (eds.) The Role of Regions? Networks, Scale, Territory, pp. 85-102. Kristianstad Boktryckeri, Kristianstad (2011)

14. Kühn, M., Bernt, M.: Peripheralization and power - theoretical debates. In: Fischer-Tahir, A., Naumann, M. (eds.) Peripheralization, pp. 302-317. Springer VS, Wiesbaden (2013)

15. Sassen, S.: Expulsions. Harvard University Press, Massachusetts (2014)

16. Perroni, M.G., Gouvea da Costa, S.E., Pinhero de Lima, E., Vieira da Silva, W., Sant Anna Ramos Vosgerau, D.: Proposal of a method for review and content analysis of literature: the case of industrial energy efficiency. In: 26th Annual Conference on POMS, pp. 1-10 (2015)

17. Glossary of Cochrane Community: Systematic review (2019)

18. Oppido, S., Ragozino, S.: Unbalanced development and peripheralisation processes: a testing phase to map studies. In: AESOP Annual Congress Venice 2019 Planning for Transition, Book of Paper, pp. 3381-3393 (2019)

19. Bramer, W.M., Rethlefsen, M.L., Kleijnen, J., Franco, O.H.: Optimal database combinations for literature searches in systematic reviews: a prospective exploratory study. Syst. Rev. 6 (245), 1-12 (2017)

20. Moher, D., Liberati, A., Tetzlaff, J., Altman, D.G., Group, T.P.: Linee guida per il reporting di revisioni sistematiche e meta-analisi: il PRISMA Statement. Evidence 7(6), 1-8 (2015)

21. Barca, F.: An Agenda for a Reformed Cohesion Policy. A Place-Based Approach to Meeting European Union Challenges and Expectations (2009) 
22. Barca, F., McCann, P., Rodríguez-Pose, A.: The case for regional development intervention: place-based versus place-neutral approaches. J. Reg. Sci. 52(1), 134-152 (2012)

23. Bevilacqua, C., Trillo, C., Esposito, G., Calabrò, J., Schultz, A.L., Pizzimenti, P., Maione, C.: Smart Specialization Strategies: The Role of Public Private Partnership in Planning Smarter Cities. Networked Regions and Cities in Times of Fragmentation: Developing Smart, Sustainable and Inclusive Places. Regional Studies Association (2012)

Open Access This chapter is licensed under the terms of the Creative Commons Attribution 4.0 International License (http://creativecommons.org/licenses/by/4.0/), which permits use, sharing, adaptation, distribution and reproduction in any medium or format, as long as you give appropriate credit to the original author(s) and the source, provide a link to the Creative Commons license and indicate if changes were made.

The images or other third party material in this chapter are included in the chapter's Creative Commons license, unless indicated otherwise in a credit line to the material. If material is not included in the chapter's Creative Commons license and your intended use is not permitted by statutory regulation or exceeds the permitted use, you will need to obtain permission directly from the copyright holder. 